\title{
Structural Analysis of a Cantilever Beam with Tapered Web Section through Fea
}

\author{
Tejal Patil ${ }^{\star}$ and Nagesh L Shelke
}

Department of Civil Engineering, Dr D Y Patil School of Engineering \& Technology, Department of Civil Engineering, Pune, India

\begin{abstract}
This paper examines the twisting anxieties of steel web decreased I segment cantilevers. Cantilevers with different level of decrease web broke down. The anxiety design along an I segment is recognized and the area and extent of the most extreme bending anxiety are talked about. The basic activity of a customary web decrease I segment under immediate or offbeat stacking is prevalently twisting, with different impacts, for example, distorting, pivot and parallel torsional clasping. The web decreased steel segment cantilever shaft is a broadly utilized auxiliary component as a part of numerous fields of use in light of its various great properties. FEA study on the conduct of steel l-segment (200 mm $\times 100 \mathrm{~mm}$ and $5 \mathrm{~m}$ length with a vertical heap of $500 \mathrm{~kg}$ ) with straight web under stacking is displayed in this course. The examination is made with I segment having same dimensioned level web. The study incorporates bending execution, sidelong torsional clasping.
\end{abstract}

It is presumed that steel bar with decreased web segment has higher imperviousness to twisting, sidelong torsional clasping contrasted with that of an area with level web segment cantilever bar. The point of turn is likewise diminished with increment in decreased proportion. 3:2 decrease proportions are reasonable as the proportionate anxiety is less for this proportion.

Keywords: Bending; Lateral torsional buckling; An angle of twist, Tapered the web; Web thickness

\section{Introduction}

At the point when a cantilever bar is stacked, it will divert vertically. On the off chance that the pillar does not have adequate parallel solidness or sidelong backing along its length, the shaft will likewise avoid out of the plane of stacking. These two distortions are reliant: when the shaft redirects along the side, the connected minute applies a segment torque about the diverted longitudinal hub which causes the pillar to wind. This conduct, which is imperative for since a long time ago excessive I-bars whose resistances to sidelong twisting and torsion are low, is called parallel torsional clasping [1-3]

I-area pillars are generally utilized as a part of cutting edge development because of their basic proficiency. The principle highlight of an I-area shaft is the mono-symmetry of the cross-segment. For most I-area cantilever pillars conveying gravity stacking the rib is situated at the top, in which case the spine is in strain and the un-solidified bit of the web is under pressure. Since the impartial hub of an I segment is nearer to the spine the most extreme compressive anxiety in the web is much higher than the greatest elastic anxiety in the rib. This implies such pillars come up short by compressive anxiety and the lateraltorsional or lateral-distortional clasping could be one of the principle disappointment modes [4,5].

Steel web decreased cantilevers are utilized on account of their tasteful elements and lightweight. They are fundamentally proficient in light of the fact that the web is decreased along the bar to nearly coordinate the variety of the bowing snapshot of the pillar. The profundity of the bar is biggest at the settled backing, where its bowing minute is most prominent and step by step diminishes towards the free end [2].

At present, the web decreased meager walled I segment is a standout amongst the most well-known decreased segments utilized as a part of practice. The quality of along the side excessive dainty walled bars is oftentimes represented by the horizontal clasping (or flexural-torsional clasping) disappointment and henceforth broad studies were centered on the sidelong clasping of meagre walled shafts. The greater parts of these studies have been worried about kaleidoscopic shafts, and just a couple of examinations are on decreased pillars [6].

\section{Proposed Design}

A web decreased I segment is built up by welding flanges and a web of the straight section. The main purpose especially is to extend to out-of-plane stiffness and shear buckling strength while not the employment of vertical stiffeners. It permits the employment of skinny plate web while not the requirement of stiffener so significantly reducing the value of fabrication. Since there's no customary style of methodology for the new section, the research has been carried out to develop a complete design guide based on the analytical and experimental study [3]

The design concept of web decreased I segment is not much different from the configuration of traditional welded steel areas. In just about all cases, the webs for both sections are classified as slender while the flanges are a semi-conservative segment. The derivation of the design shear capacity of tapered web sections depends on the aftereffects of exploratory and hypothetical study and is the major part of the research program [3] (Figure 1).

The advantage of such design is to reduce bending and lateral

*Corresponding author: Tejal Patil, Department of Civil Engineering, Dr D Y Patil School of Engineering and Technology, Department of Civil Engineering, Pune, India, Tel: +918421659137; E-mail: tejalnitinpatil@gmail.com

Received September 12, 2016; Accepted September 20, 2016; Published September 30, 2016

Citation: Patil T, Shelke NL (2016) Structural Analysis of a Cantilever Beam with Tapered Web Section through Fea. J Steel Struct Constr 2: 119. doi: 10.4172/24720437.1000119

Copyright: ( 2016 Patil T, et al. This is an open-access article distributed under the terms of the Creative Commons Attribution License, which permits unrestricted use, distribution, and reproduction in any medium, provided the original author and source are credited. 
Citation: Patil T, Shelke NL (2016) Structural Analysis of a Cantilever Beam with Tapered Web Section through Fea. J Steel Struct Constr 2: 119. doi: $10.4172 / 2472-0437.1000119$

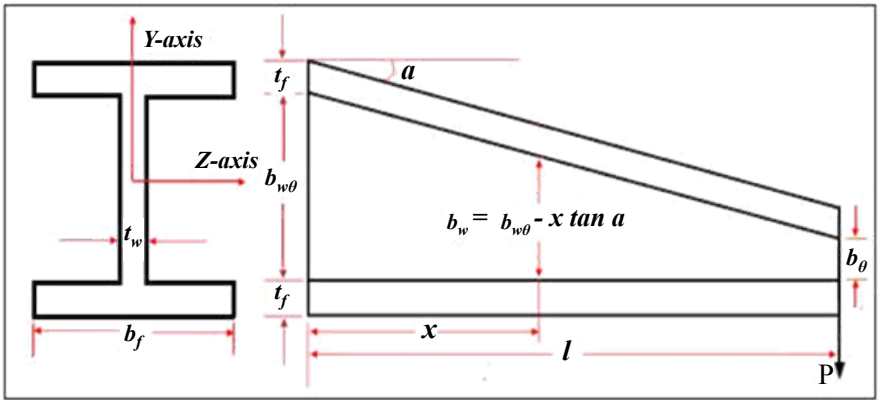

Parameter selection

For Taper Beam

a. Taper ratio - 200:200, 300:200, 400:200, 500:200

b. Cross section of cantilever - Symmetrical I beam section

c. Flange Thickness $-10 \mathrm{~mm}$

d. Web Thickness $-5.7 \mathrm{~mm}$

e. Cantilever Length $-5000 \mathrm{~mm}$

Figure 1: Taper ratio calculation.

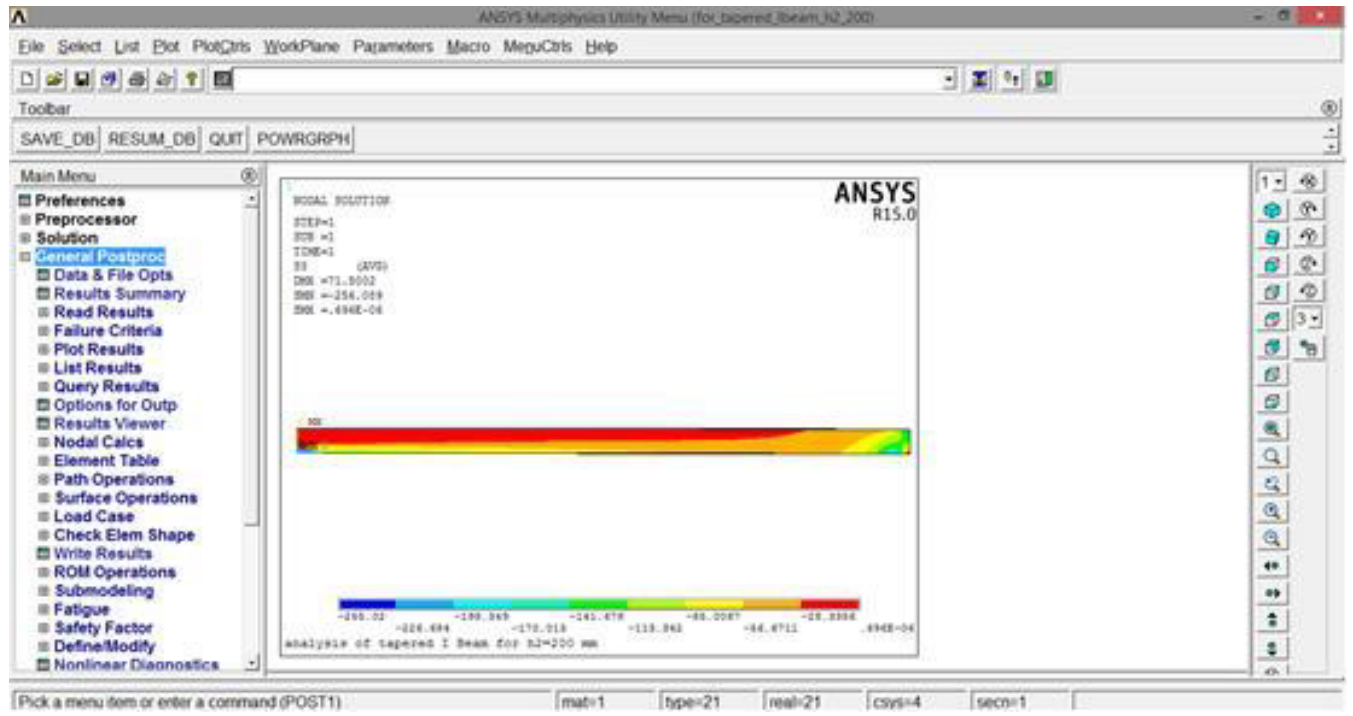

Figure 2: Contour image - for taper ration 200:200.

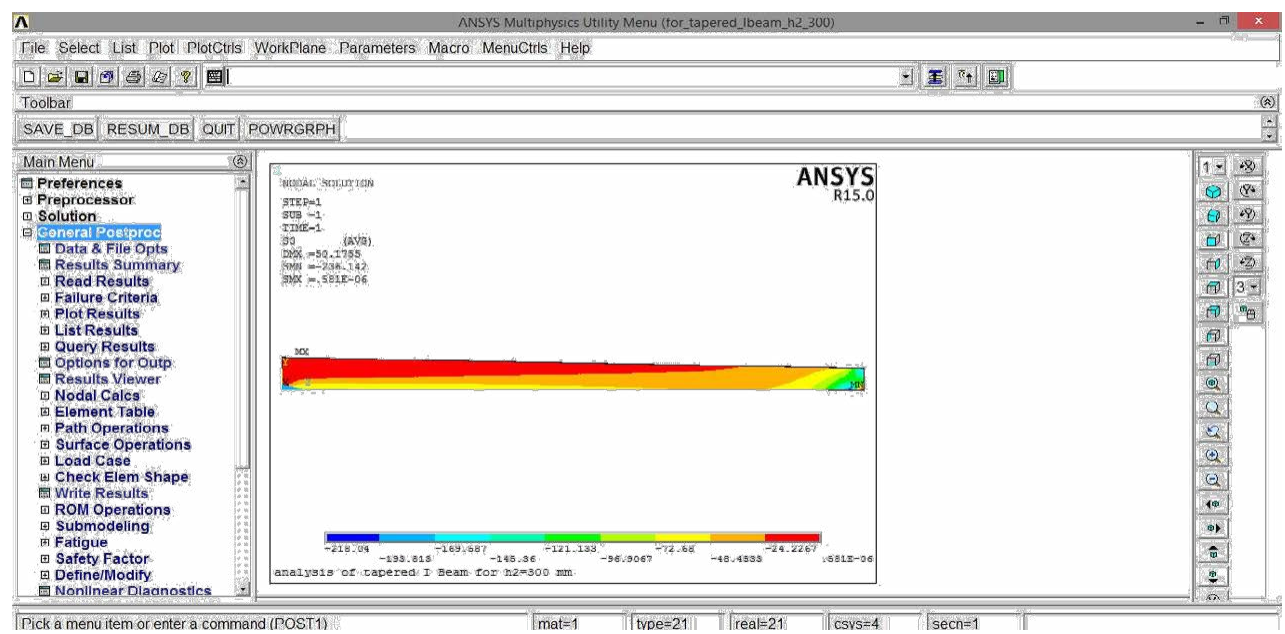

Figure 3: Contour image - for taper ration 300:200 
Citation: Patil T, Shelke NL (2016) Structural Analysis of a Cantilever Beam with Tapered Web Section through Fea. J Steel Struct Constr 2: 119. doi: $10.4172 / 2472-0437.1000119$

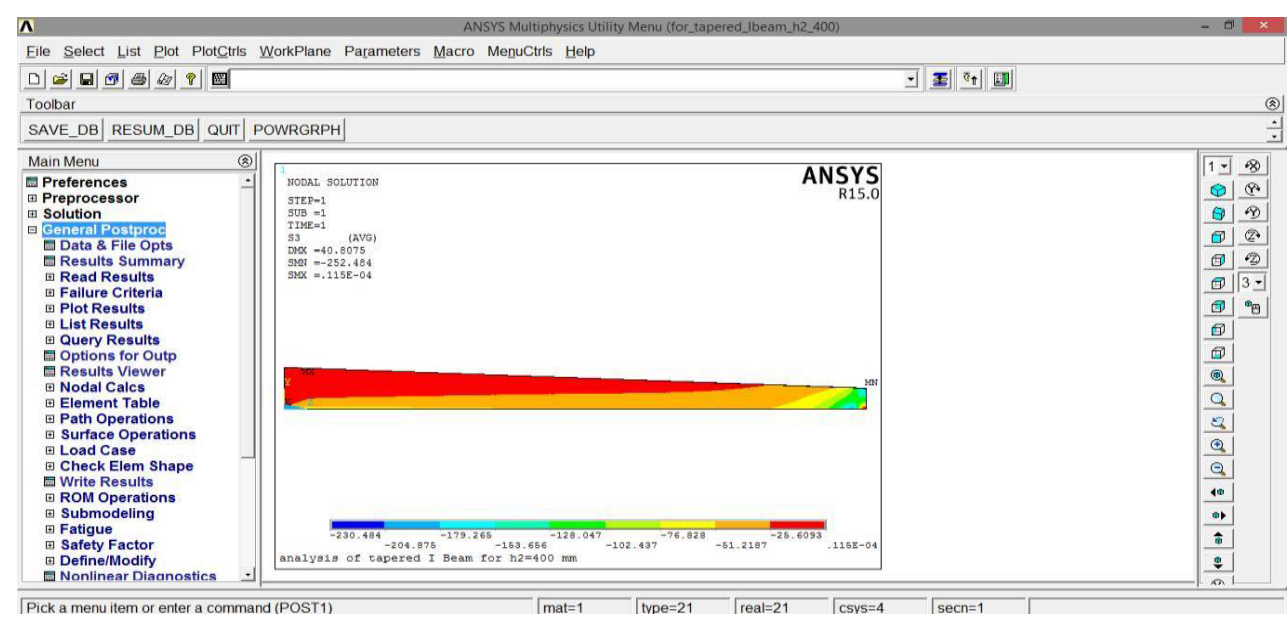

Figure 4: Contour image - for taper ration 400:200.

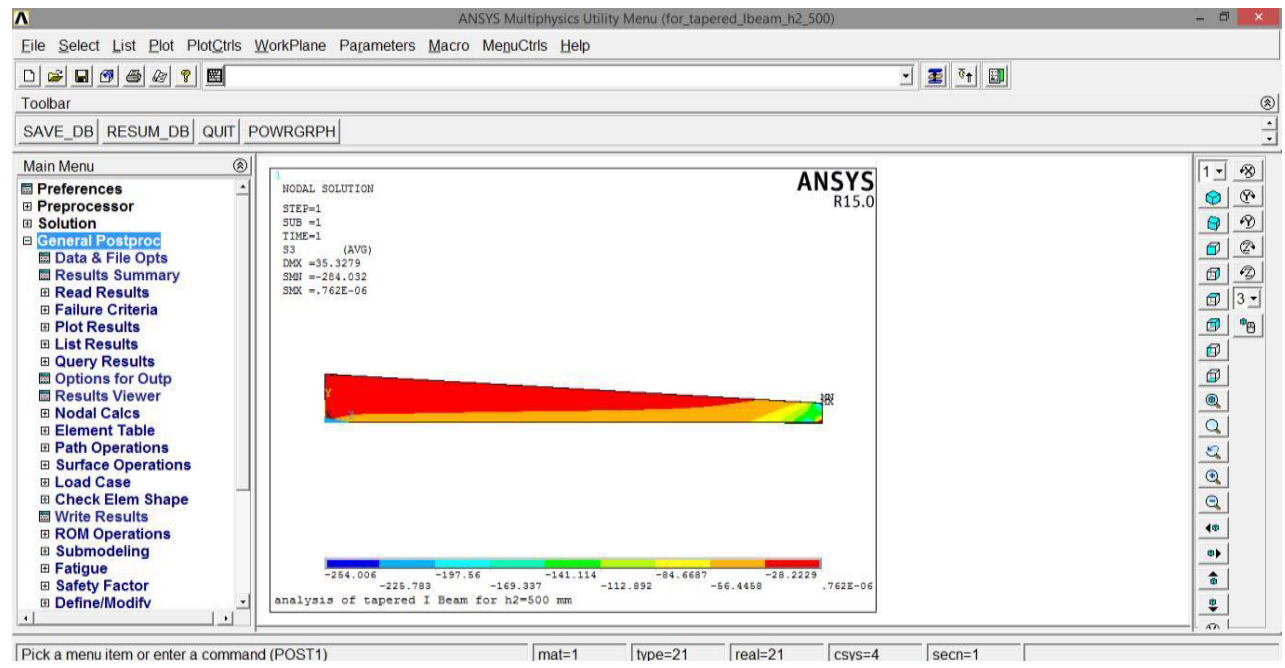

Figure 5: Contour image - for taper ration 500:200.

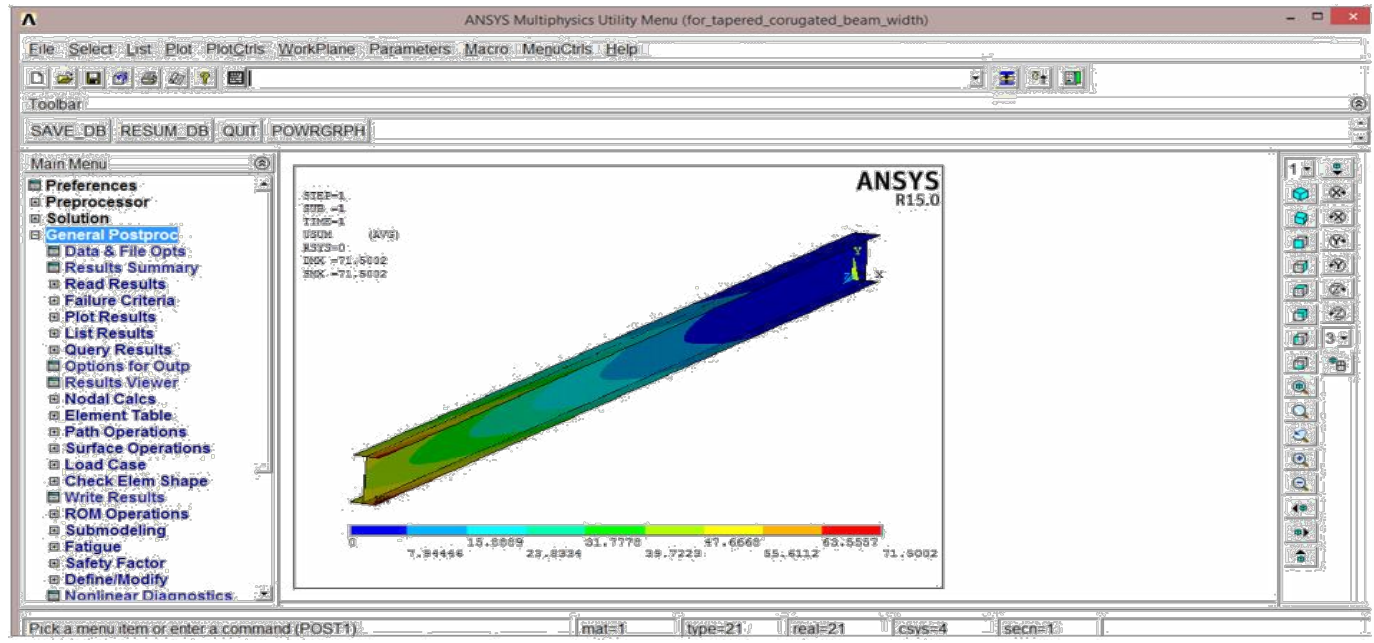

Figure 6: Stress concentration - for taper ration 200:200. 
Citation: Patil T, Shelke NL (2016) Structural Analysis of a Cantilever Beam with Tapered Web Section through Fea. J Steel Struct Constr 2: 119. doi: $10.4172 / 2472-0437.1000119$

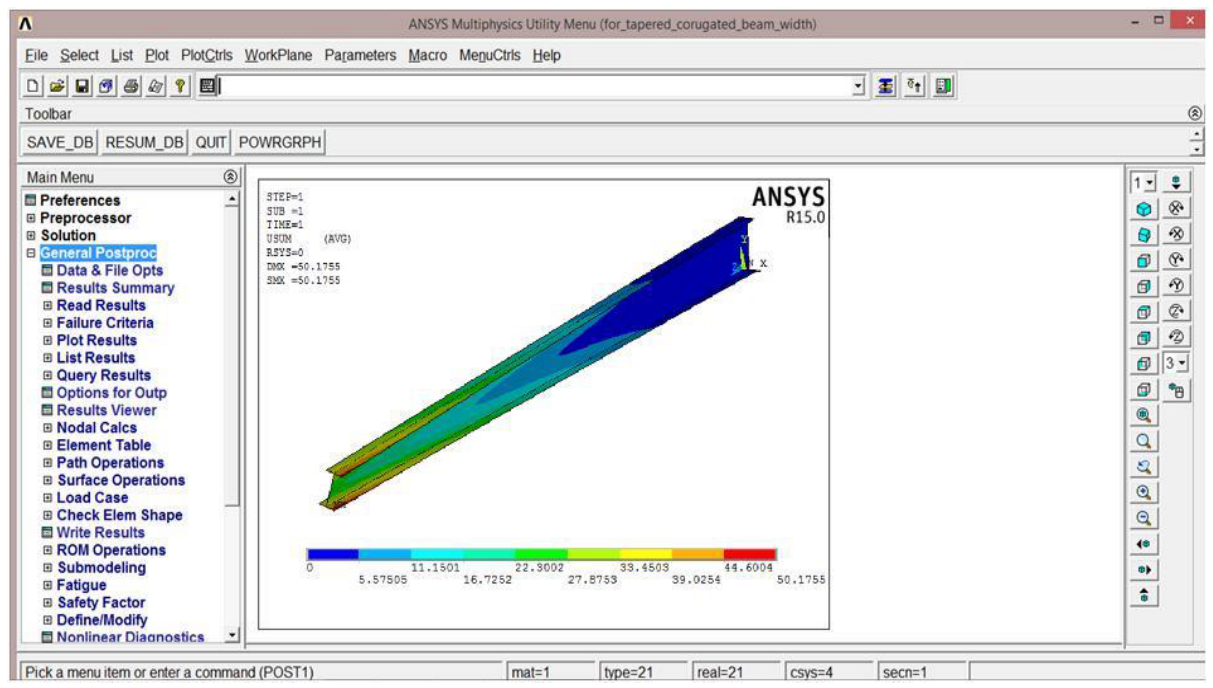

Figure 7: Stress concentration - for taper ration 300:200.

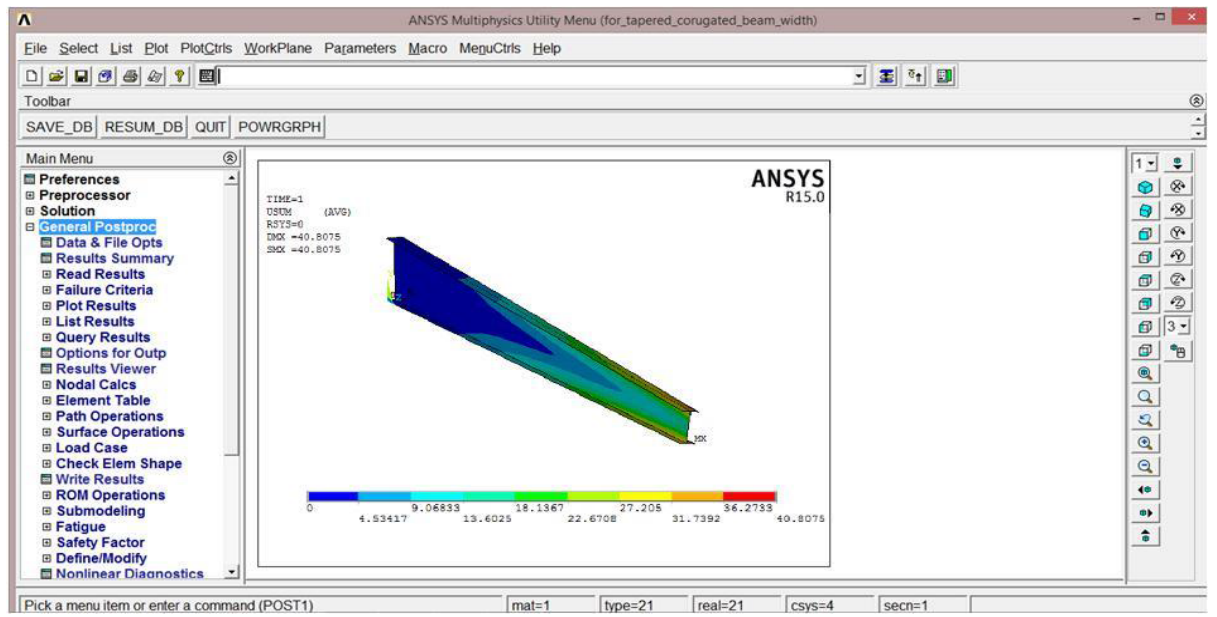

Figure 8: Stress concentration - for taper ration 400:200.

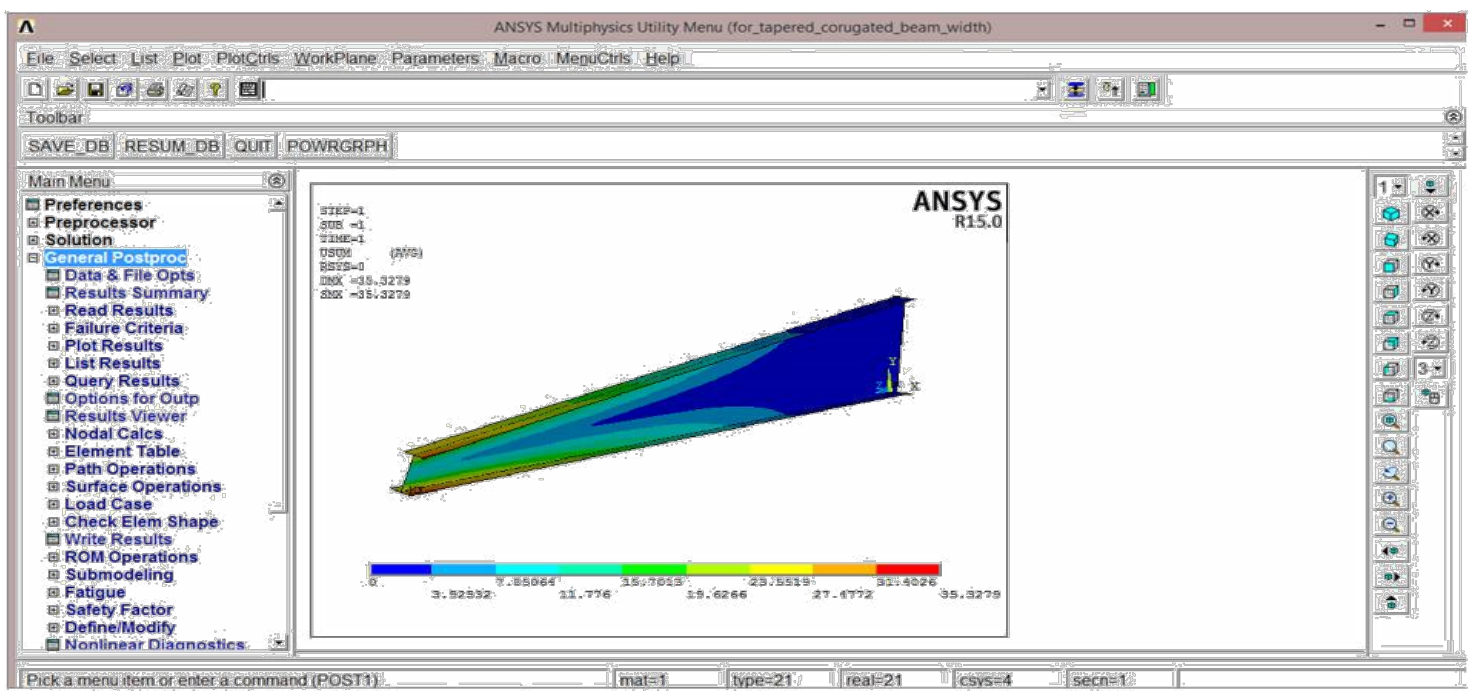

Figure 9: Stress concentration - for taper ration 500:200. 
Citation: Patil T, Shelke NL (2016) Structural Analysis of a Cantilever Beam with Tapered Web Section through Fea. J Steel Struct Constr 2: 119. doi: $10.4172 / 2472-0437.1000119$

Page 5 of 6

torsional buckling in a cantilever beam (Such as in Jib Crane trolley may stuck-up on cantilever beam due to LTB subjected to eccentric loading application). A web decreased I segment are usually adapted in order to optimize the load capacity at each cross section taking into account the respective distribution of stress.

\section{Finite Element Analysis}

The limited component study was completed on the trapezoidal and straight web area utilizing CAE programming. In this concentrate, all demonstrates were accepted to clasp under immaculate conditions, where there is no underlying imperfectness and unusual burden. Stacking conditions are additionally same for all demonstrates, two sorts of burdens are viewed as, one is point load at the free end and selfweight of a shaft. To guarantee the heap is connected through the web, the hubs for the backing will be obliged in its $\mathrm{x}, \mathrm{y}$, and $\mathrm{z}$ interpretation at the backing. The suppositions utilized as a part of the straight clasping investigation are that the direct solidness lattice does not change preceding clasping and that the anxiety firmness framework is essentially several of its underlying quality.

The primary target of an Eigenvalue investigation is to get the qualities imperviousness to sidelong torsional clasping and bowing. Eigenvalue clasping investigation is a direct examination that might be connected to moderately solid structures with a specific end goal to gauge the greatest burden that can be upheld to basic unsteadiness or breakdown.

\section{Modelling}

CATIA is utilized to make the models and is characterized as far as geometric elements that must be subdivided into limited components for an arrangement. This procedure of subdivision is called coinciding. Network datasets contain data about component sorts, component discretization and cross section sort. The I segments models were appointed ungraded mellow steel for its material property with Young's modulus, $\mathrm{E}=2.1 \times 105 \mathrm{~N} / \mathrm{mm}^{2}$, shear modulus, $\mathrm{G}=79 \times 103 \mathrm{~N} / \mathrm{mm}^{2}$ and Poisson proportion of 0.3 .

\section{Analysis of taper I beam with straight web}

Steel web decreased cantilevers are utilized on account of their stylish elements and lightweight. They are basically proficient in light of the fact that the web is decreased along the bar to nearly coordinate the variety of the bowing snapshot of the shaft. The profundity of the pillar is biggest at the settled backing, where its twisting minute is most noteworthy and slowly diminishes towards the free end.

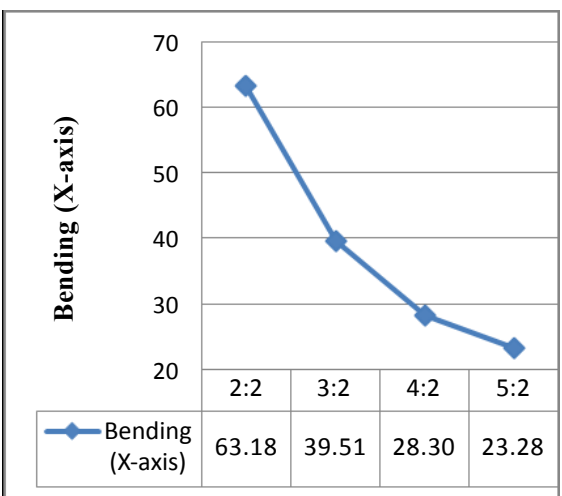

Figure 10: Effect of taper ration on bending in x-axis
Albeit generally utilized, no outline strategy is accessible for steel web decreased tee segment cantilevers. This proposition additionally explores the twisting anxieties of such bars. Connections between the bowing, parallel torsional clasping, point of turn and distinctive burdens and the level of decrease were examined. This paper examines the twisting anxieties, shear hassles and comparable burdens of steel web decreased I segment cantilevers. Cantilevers with different level of decrease were dissected. The anxiety design along the bar is recognized and the area and greatness of the most extreme twisting anxiety are examined (Figures 2-8).

\section{FEA Results}

FEA aftereffects of Bending in X-pivot $(\mathrm{mm})$ and LTB in Z-hub $(\mathrm{mm})$ with point of turn (Deg) of decrease I-pillar with straight web for whimsical stacking $(\mathrm{e}=100 \mathrm{~mm})$ (Table 1$)$.

\begin{tabular}{|c|c|c|c|c|c|c|c|c|}
\hline \multirow[t]{3}{*}{ h/h' } & \multirow{3}{*}{$\begin{array}{l}\text { Span } \\
(\mathrm{mm})\end{array}$} & \multirow{3}{*}{$\begin{array}{l}\text { Web } \\
\text { Thk } \\
(\mathrm{tw}) \\
(\mathrm{mm})\end{array}$} & \multicolumn{6}{|c|}{ Straight Beam } \\
\hline & & & \multirow{2}{*}{$\begin{array}{c}\text { X-axis } \\
\text { Bending } \\
\text { (mm) }\end{array}$} & \multicolumn{2}{|c|}{ Z-axis } & \multirow{2}{*}{$\begin{array}{c}\text { Shear } \\
\text { Stresses } \\
\text { (MPa) }\end{array}$} & \multirow{2}{*}{$\begin{array}{l}\text { Equivalent } \\
\text { stress } \\
\text { (Mpa) }\end{array}$} & \multirow{2}{*}{$\begin{array}{c}\text { Bending } \\
\text { stress } \\
\text { (Mpa) }\end{array}$} \\
\hline & & & & $\begin{array}{l}\text { LTB } \\
(\mathrm{mm})\end{array}$ & $\begin{array}{c}\text { Angle } \\
\text { of Twist } \\
\text { (Deg) }\end{array}$ & & & \\
\hline $200 / 200$ & 5000 & 5.7 & 63.18 & 58.17 & 33.33 & 106.44 & 255.02 & 227.60 \\
\hline $300 / 200$ & 5000 & 5.7 & 39.50 & 45.32 & 25.91 & 109.59 & 229.57 & 218.04 \\
\hline $400 / 200$ & 5000 & 5.7 & 28.30 & 38.60 & 22.12 & 113.11 & 236.07 & 230.48 \\
\hline $500 / 200$ & 5000 & 5.7 & 23.27 & 34.17 & 19.58 & 116.57 & 250.79 & 264.00 \\
\hline
\end{tabular}

Table 1: FEA aftereffects of Bending in X-pivot $(\mathrm{mm})$ and LTB in Z-hub $(\mathrm{mm})$ with point of turn (Deg) of decrease I-pillar with straight web for whimsical stacking $(\mathrm{e}=100 \mathrm{~mm})$.

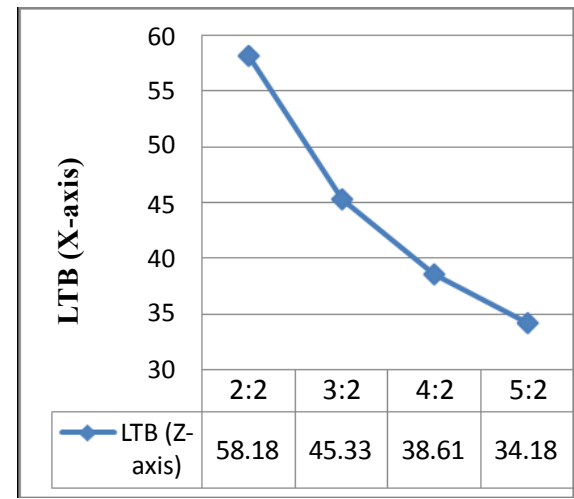

Figure 11: Effect of taper ration on LTB in z-axis.

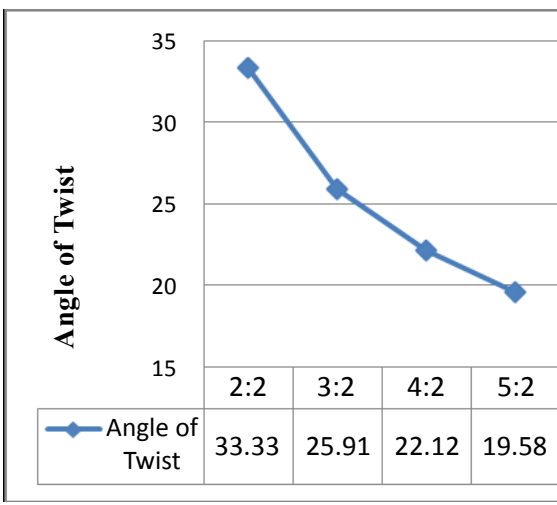

Figure 12: Effect of taper ration on angle of twist. 
Citation: Patil T, Shelke NL (2016) Structural Analysis of a Cantilever Beam with Tapered Web Section through Fea. J Steel Struct Constr 2: 119. doi: $10.4172 / 2472-0437.1000119$

Page 6 of 6

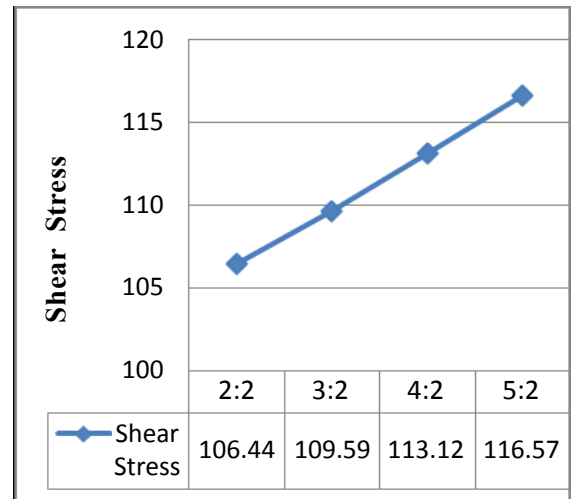

Figure 13: Effect of taper ration on shear stress.

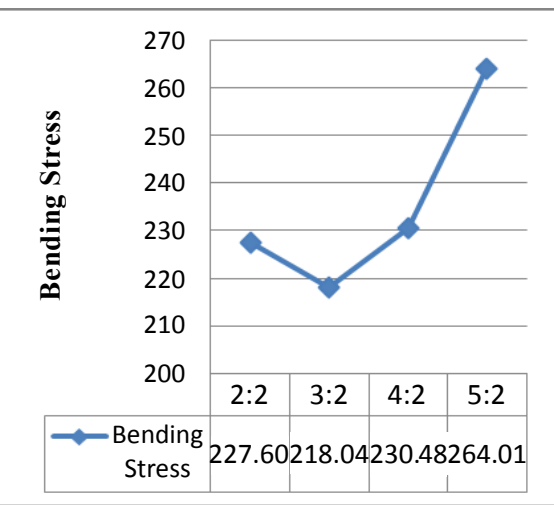

Figure 14: Effect of taper ration on bending stress.

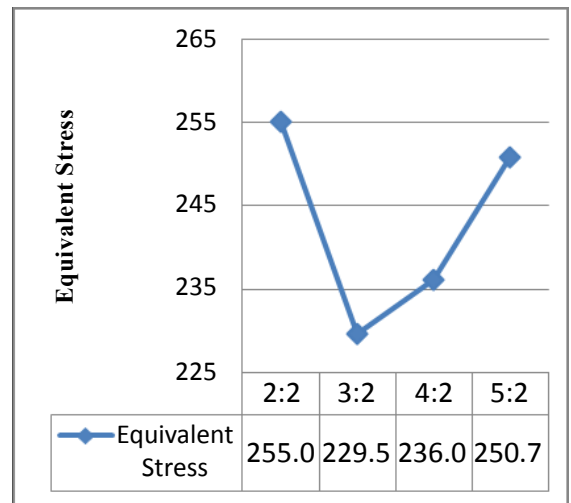

Figure 15: Effect of taper ration on equivalent stress

\section{Graph (Figures 9-15)}

\section{Conclusion}

A finite element analysis is done on the behavior of steel beam section taper ratio and compared the same with regular steel section when applied a load at free end, and the following points are concluded:

1. Taper beam steel section has higher resistance to bending, lateral torsional buckling compared to that of section with flat web section cantilever beam.

2. The angle of twist is reduced with the increase in taper ration hence twist is reduces.

3. Shear stress increases as the taper ration is increased.

4. Varying cross section of beam varies the results. Symmetrical I section beam gives better results than unsymmetrical I section, $\mathrm{T}$ section, $\mathrm{C}$ section.

5. As equivalent stress is reduced $1 \mathrm{~s}$ and then as taper ratio increases equivalent stress also increases. Only 3:2 taper ratio gives better result for not only shear, bending and equivalent stress, hence consider 3:2 is suitable ratio.

\section{References}

1. Andrade $P$, Providência D, Camotim B (2010) Elastic lateral-torsional buckling of restrained web-tapered I-beams. Computers and Structures 88: 1179-1196.

2. Kim B, Oliver A, Vyse A (2013) Bending stresses of steel web tapered tee section cantilevers. Journal of Civil Engineering and Architecture 7: 1329-1342.

3. Denan F, Osman MH, Saad S (2010) The study of lateral torsional buckling behaviour of a beam with trapezoid web steel section by experimental and finite element analysis. International Journal of Research and Reviews in Applied Sciences 2: 232-240.

4. Trahair NS (2014) Bending and buckling of tapered steel beam structures. Engineering Structures 59: 229-237.

5. Yuan WB, Kim BY, Chen CY (2013) Lateral-torsional buckling of steel web tapered tee-section cantilevers. J Constr Steel Res 87: 31-37.

6. Lei Z, Shu TG (2008) Lateral buckling of web-tapered I-beams: A new theory. J Constr Steel Res 64: 1379-1393. 